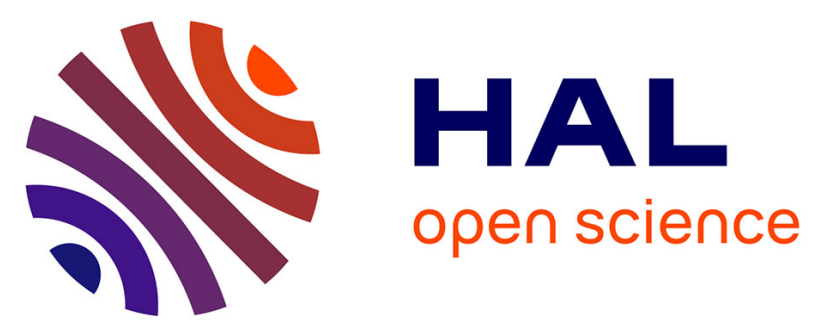

\title{
Sub-ppb detection of benzene using cantilever-enhanced photoacoustic spectroscopy with a long-wavelength infrared quantum cascade laser
}

Juho Karhu, Hadrien Philip, Alexei Baranov, Roland Teissier, Tuomas Hieta

\section{To cite this version:}

Juho Karhu, Hadrien Philip, Alexei Baranov, Roland Teissier, Tuomas Hieta. Sub-ppb detection of benzene using cantilever-enhanced photoacoustic spectroscopy with a long-wavelength infrared quantum cascade laser. Optics Letters, 2020, 45 (21), pp.5962. 10.1364/OL.405402 . hal-03015126

\author{
HAL Id: hal-03015126 \\ https://hal.science/hal-03015126
}

Submitted on 20 Nov 2020

HAL is a multi-disciplinary open access archive for the deposit and dissemination of scientific research documents, whether they are published or not. The documents may come from teaching and research institutions in France or abroad, or from public or private research centers.
L'archive ouverte pluridisciplinaire HAL, est destinée au dépôt et à la diffusion de documents scientifiques de niveau recherche, publiés ou non, émanant des établissements d'enseignement et de recherche français ou étrangers, des laboratoires publics ou privés. 


\title{
Sub-ppb detection of benzene using cantilever-enhanced photoacoustic spectroscopy with a long-wavelength infrared quantum cascade laser
}

\author{
Juho Karhu ${ }^{1,}$, , Hadrien Philip ${ }^{2}$, Alexei Baranov ${ }^{2}$, Roland Teissier ${ }^{2}$, and Tuomas Hieta ${ }^{3}$ \\ ${ }^{1}$ Department of Chemistry, University of Helsinki, P.O. Box 55, Fl-00014, Helsinki, Finland \\ ${ }^{2}$ IES, University of Montpellier, CNRS, 34095 Montpellier, France \\ ${ }^{3}$ Gasera Ltd., Lemminkäisenkatu 59, Fl-20520, Turku, Finland \\ ${ }^{*}$ Corresponding author: juho.karhu@helsinki.fi
}

Compiled September 23, 2020

We report a novel photoacoustic spectrometer for trace gas sensing of benzene. A quantum cascade laser emitting at the wavelength $14.8 \mu \mathrm{m}$ is used as the light source in the spectroscopic detection. This wavelength region contains the strongest vibrational band of benzene, which is free of spectral overlap from common trace gases, making it a strong candidate for sensitive benzene detection. Cantilever-enhanced photoacoustic spectroscopy is used for detection. This simple and robust measurement setup can reach a benzene detection limit below 1 ppb. ๑ 2020 Optical Society of America

http://dx.doi.org/10.1364/ao.XX.XXXXXX

Cantilever-enhanced photoacoustic spectroscopy (CEPAS) is used in sensitive trace gas detection, with detection limits demonstrated at parts-per-trillion (ppt) level and below [1, 2], and it has been applied to measurements of various volatile organic compounds (VOC) $[3,4]$. Of the many VOC, there is substantial interest in measuring benzene $\left(\mathrm{C}_{6} \mathrm{H}_{6}\right)$. It is used widely in industry but it is a known carcinogen and worker exposure is tightly regulated [5]. Benzene is also a component in gasoline, and a major exposure path to the general public is from traffic and driving [6]. Many of the most sensitive benzene detection methods rely on gathering a sample and sending it for offline analysis in a laboratory, although sensitive sensors are also being developed [7]. Optical detection methods, based on spectroscopy, would provide an opportunity for development of sensitive portable instruments, which could be used in measurements on the field or set up for long term autonomous data collection.

Most of the optical benzene trace gas detectors focus on the strong infrared band located at about $3 \mu \mathrm{m}$ [8]. Detection limits in the low parts-per-billion ( $\mathrm{ppb}$ ) range have been reached, for example, using a difference frequency generation (DFG) light source [9] and using an optical parametric oscillator together with CEPAS [3]. However, the benzene absorption band at $3 \mu \mathrm{m}$ has severe spectral overlap with many other VOCs, most importantly toluene and xylene isomers, which are typical interferents in benzene measurements. For example, in the prior CEPAS study for benzene detection, the detection limit increased by an order of magnitude when this interference was properly accounted for [3].

In this letter, we describe a novel CEPAS spectrometer, which takes advantage of the strongest benzene infrared band, $v_{4}$, located at about $14.8 \mu \mathrm{m}$. This band is accessed using a longwavelength quantum cascade laser (QCL). The $v_{4}$ band has been applied before in benzene sensing, using a DFG source and a cryogenically cooled diode laser, but the reported detection limits have been in the part-per-million (ppm) range [10, 11]. A detection limit in the low ppb range was reached with a Fouriertransform infrared spectrometer, but only after sample preconcentration of up to $40 \mathrm{~min}$ [12]. In addition to being the strongest vibrational transition of benzene, the $v_{4}$-band is also significantly narrower than the other benzene infrared bands, and does not overlap with the spectra of typical interfering species. There is, however, spectral interference from a nearby $\mathrm{CO}_{2}$ transition. Nevertheless, the spectrometer described in this letter is able to reach a detection limit in the range of $1 \mathrm{ppb}$ and below in the presence of varying ambient $\mathrm{CO}_{2}$ concentration. Figure 1 shows spectra of benzene and $\mathrm{CO}_{2}$ around the target wavelength range, simulated using the SPECTRA online tool from data available in the GEISA database [13].

A schematic picture of the simple measurement setup is depicted in Fig. 2. The used light source was a continuous-wave QCL, developed at the University of Montpellier. The used QCL is based on the InAs and AlSb materials, which demonstrated the first and only semiconductor lasers operating in a continuous wave at room temperature in the long wavelength mid-infrared [14]. A device with a distributed feedback grating [15] was fabricated in order to obtain single mode emission at the frequency of the $v_{4}$ band of benzene. The QCL operated on a water-cooled thermoelectric cooler. The accessible tuning range was from $671.5 \mathrm{~cm}^{-1}$ to $675 \mathrm{~cm}^{-1}$ and the output power was up to $5 \mathrm{~mW}$. The operational temperature used in the experiments was about $250 \mathrm{~K}$. The laser beam passed through a $9 \mathrm{~cm}$ long photoacoustic cell with a cantilever microphone detector. The inner diameter of the cell was $4 \mathrm{~mm}$. The QCL beam was focused at about $20 \mathrm{~cm}$ away from the output window so that the beam diameter was smaller than the cell inner diameter, over a distance of $10 \mathrm{~cm}$. 


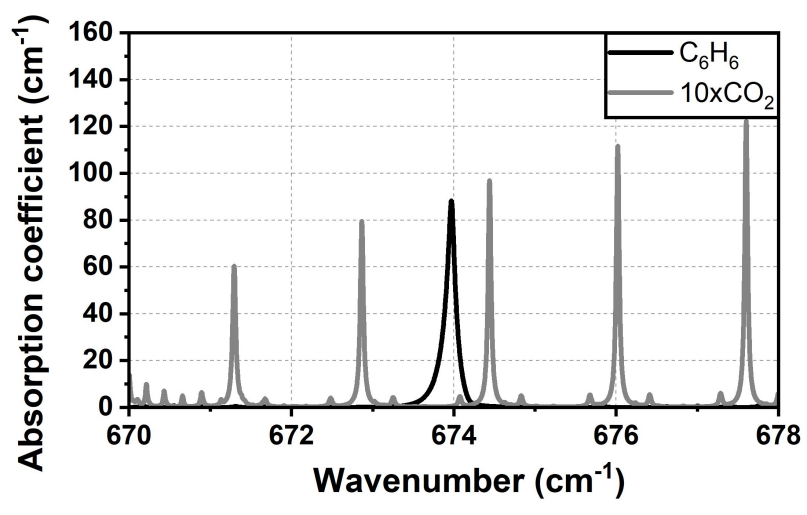

Fig. 1. Simulated spectra of pure benzene (black) and $\mathrm{CO}_{2}$ (grey) at 200 mbar. The $\mathrm{CO}_{2}$ spectrum has been multiplied by 10 for easier comparison.

The cell windows were anti-reflection coated $\mathrm{ZnSe}$ windows. The reflectivity of the coating was specified only up to $12 \mu \mathrm{m}$, but the transmission was measured to be above $80 \%$ over the whole measurement wavelength range. The optical power after the photoacoustic cell was measured with a thermopile detector, to normalize the photoacoustic response. The gas pressure inside the cell was 200 mbar and the cell was stabilized to the temperature of $50^{\circ} \mathrm{C}$. Benzene gas samples were generated by mixing compressed air with gas containing $52 \mathrm{ppm}$ of benzene in nitrogen balance. When a sample clean of benzene was required for reference measurements, the compressed air was filtered through active carbon.

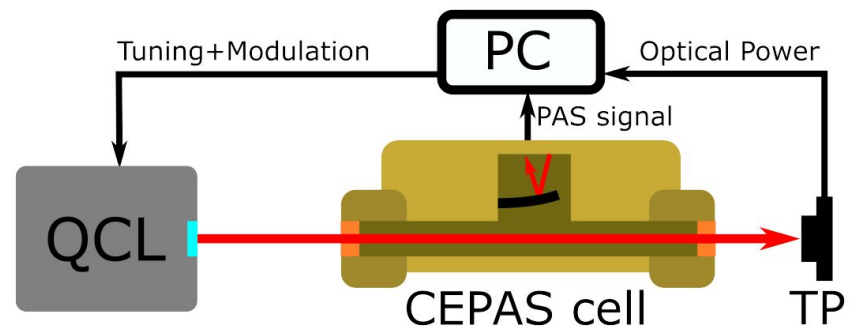

Fig. 2. Schematic picture of the measurement setup. The laser beam from a QCL emitting at $14.8 \mu \mathrm{m}$ is sent through a photoacoustic cell containing the sample gas and a cantilever microphone with optical readout. A thermopile detector (TP) is used to measure the power of the laser after the photoacoustic cell. The data recording and the laser control is done using a LabVIEW program running on a PC.

Benzene was detected from the Q-branch of the $v_{4}$ band at about $673.973 \mathrm{~cm}^{-1}$ in wavenumber. This spectral region is mostly clear from obvious interferents, except there is a $\mathrm{CO}_{2}$ line at $674.075 \mathrm{~cm}^{-1}$, which is partially overlapping with the benzene Q-branch. To reduce the interference from the $\mathrm{CO}_{2}$ transition, the detection was done using wavelength modulation absorption spectroscopy (WMAS), with a modulation frequency of $60 \mathrm{~Hz}$.

The laser wavelength was tuned by the laser current. The wavelength axis was referenced using the $\mathrm{CO}_{2}$ line at $674.075 \mathrm{~cm}^{-1}$ and the benzene Q-branch. The signal is demodulated at the second harmonic of the modulation frequency. The
WMAS spectrum near the benzene band is shown in Fig. 3 for benzene and $\mathrm{CO}_{2}$. In the benzene concentration measurements, ten points were first measured on top of the $\mathrm{CO}_{2}$ transition in order to align the wavelength axis, as well as to record the photoacoustic signal, which corresponds to the $\mathrm{CO}_{2}$ concentration, since there is significant absorption from the tail of the $\mathrm{CO}_{2}$ line over the benzene Q-branch. The laser current was then shifted by a fixed offset value to measure the spectral response at the wavelength of the benzene Q-branch. Total of 23 wavelength steps were recorded around the center of the benzene absorption feature, over a wavenumber range of about $0.04 \mathrm{~cm}^{-1}$. Each measurement point was averaged for about $1.8 \mathrm{~s}$. A single scan, which consisted of the gas exchange, the $\mathrm{CO}_{2}$ line measurement and the scan over the benzene Q-branch, took about $70 \mathrm{~s}$.

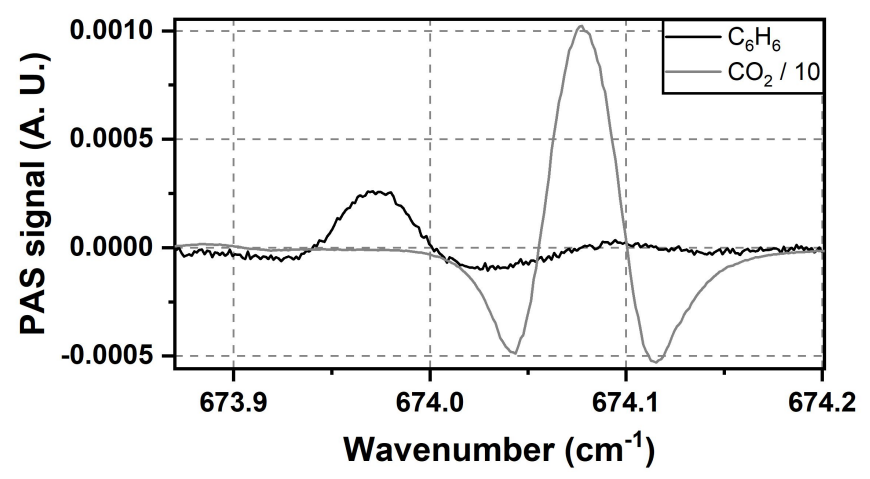

Fig. 3. Photoacoustic wavelength modulation spectrum of $200 \mathrm{ppb}$ of benzene in nitrogen (black) and $\mathrm{CO}_{2}$ in air (grey). The $\mathrm{CO}_{2}$ spectrum has been scaled by dividing the signal by 10 , for easier comparison.

In terms of the signal level, typical $\mathrm{CO}_{2}$ concentration in air results in a signal level that corresponds to about $90 \mathrm{ppb}$ of benzene at the peak of the benzene signal (Fig. 4). The $\mathrm{CO}_{2}$ signal is nearly flat over much of the benzene peak, making it relatively easy to distinguish the spectra of the two components. The $\mathrm{CO}_{2}$ contribution to the benzene signal was compensated using a $\mathrm{CO}_{2}$ reference spectrum, which had been measured from benzene-free compressed air. This reference spectrum contained the signal at the $\mathrm{CO}_{2}$ line, as well as the $\mathrm{CO}_{2}$ contribution over the benzene Q-branch. For individual scans, the $\mathrm{CO}_{2}$ reference spectrum was scaled so that the signal at the $\mathrm{CO}_{2}$ line was equal to that measured during the scan. This scaling accounts for any changes in the ambient $\mathrm{CO}_{2}$ concentration. The scaled reference spectrum was then subtracted from the benzene spectrum measured during the scan, in order to eliminate the $\mathrm{CO}_{2}$ contribution. A reference benzene spectrum was recorded with a gas sample containing $204 \mathrm{ppb}$ of benzene. Benzene concentration was calculated from the spectrum measured during a scan with a linear least-squares fit of the reference benzene spectrum, with the assumption that the photoacoustic signal depends linearly on the concentration. The linearity of the spectrometer was tested by repeating the measurement at four benzene levels. Each level was recorded for about 30 minutes. The resulting calibration curve is shown in Fig. 5 and it displays excellent linearity.

The stability of the measurement system was tested by recording benzene-free compressed air over a time period of about 60 hours. Effectively, this means fitting the benzene reference spectrum into the residual spectrum after the $\mathrm{CO}_{2}$ contribution has been subtracted from the measured spectrum. The results show 


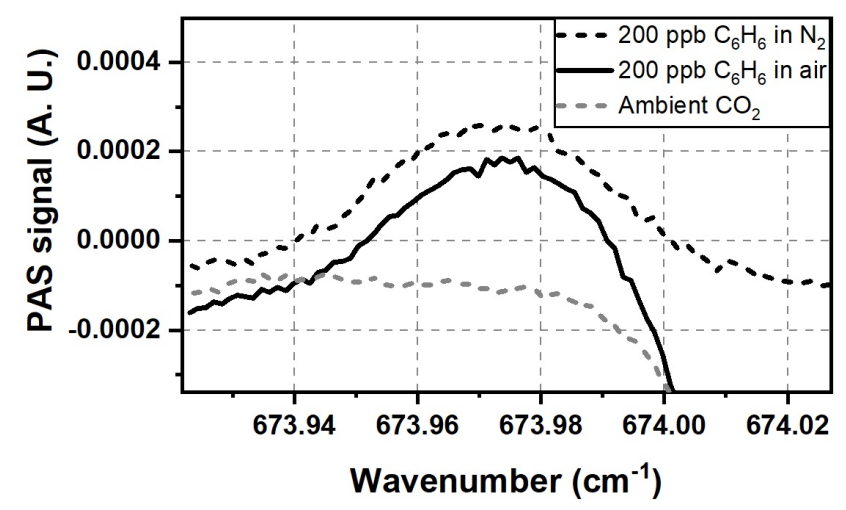

Fig. 4. Spectrum of $200 \mathrm{ppb}$ of benzene in air near the benzene absorption peak. The figure also depicts spectra for ambient $\mathrm{CO}_{2}$ and $200 \mathrm{ppb}$ of benzene in $\mathrm{N}_{2}$, to show the relative contributions from the two components.

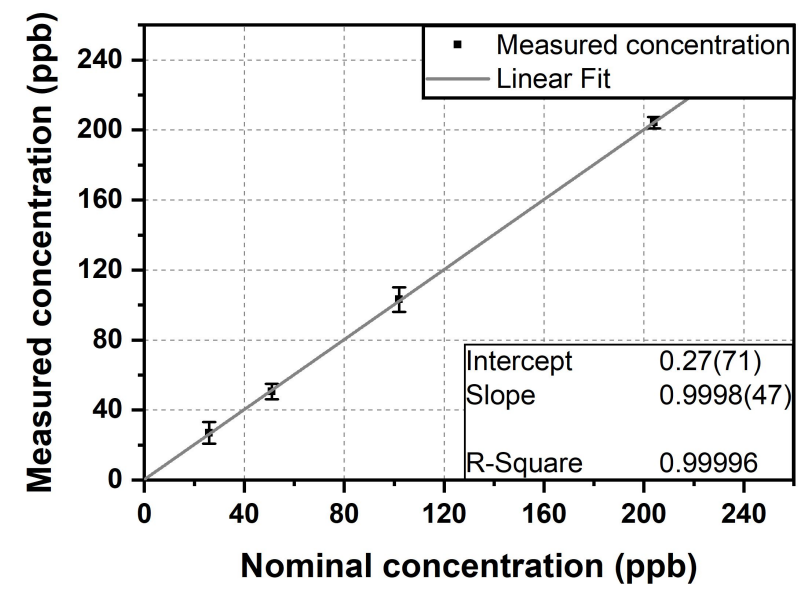

Fig. 5. Photoacoustic signal of benzene measured at different concentrations and a linear fit to the concentration data. Each concentration was measured for about 30 minutes. The reported concentration is the mean value and the error bars are statistical errors from each set of concentration data $(3 \sigma)$. The nominal concentration is calculated from the flow ratios of the mass flow controllers used to dilute the benzene sample. good long-term stability in benzene-free measurement and indicates that the $\mathrm{CO}_{2}$ spectral compensation is effective. The zero level stays nearly constant, but small drifting below ppb level can be detected. Figure 6 shows Allan deviation of the zero level measurement, together with the time trace. The Allan deviation reaches a minimum with a noise equivalent concentration of about $0.15 \mathrm{ppb}$ with about $200 \mathrm{~min}$ of averaging. Another long time trace of 15 hours was also measured with a constant benzene level of $26 \mathrm{ppb}$ and the results are shown in Fig. 7. The noise was slightly higher in this measurement, but it reaches a similar level with long averaging times.
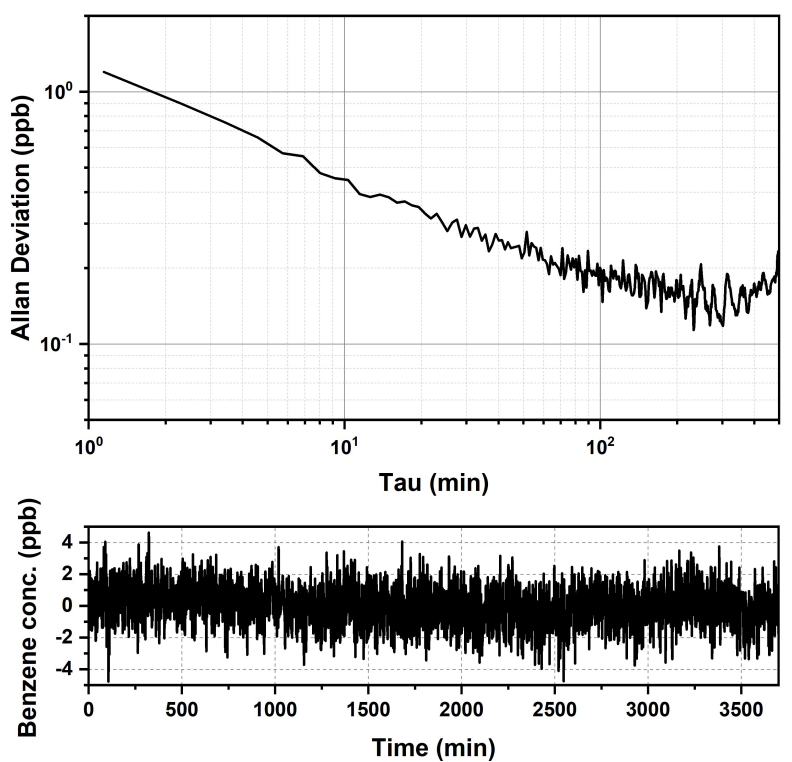

Fig. 6. Allan deviation of a benzene zero level measurement (above) and the time trace used to calculate the deviation (below).

The normalized noise equivalent absorption (NNEA) is calculated as the product $N N E A=\sigma_{\alpha} P \sqrt{t}$, where $\sigma_{\alpha}$ is the noise equivalent absorption coefficient, $P$ is the optical power and $t$ is the averaging time. To estimate $N N E A$, we scaled the maximum absorption from the benzene Q-branch, as simulated with SPECTRA for $26 \mathrm{ppb}$ of benzene at $200 \mathrm{mbar}$ [13], with the signalto-noise ratio at $100 \mathrm{~min}$ averaging time, according to Fig. 7 . The optical power within the CEPAS cell, taking into the account the window transmission, was about $2.4 \mathrm{~mW}$ in this measurement. This corresponds to NNEA of about $2.8 \times 10^{-9} \mathrm{~cm}^{-1} \mathrm{WHz}^{-1 / 2}$. For best CEPAS measurements, the NNEA is typically in the order of $10^{-10} \mathrm{~cm}^{-1} \mathrm{WHz}^{-1 / 2}[1,2]$. The higher NNEA here is mostly due to the fact that the WMAS modulation amplitude was chosen as a compromise between maximizing the benzene signal and minimizing the interference from the $\mathrm{CO}_{2}$ transition. Maximizing the WMAS signal with benzene alone would result in about six times stronger signal. It should also be noted that the averaging time used in the NNEA calculation included the $\mathrm{CO}_{2}$ line measurements and gas exchange cycles.

In conclusion, we have demonstrated a simple but sensitive spectroscopic detector for benzene, based on CEPAS and a continuous-wave QCL emitting at $14.8 \mu \mathrm{m}$. The measurement setup reaches a minimum noise equivalent benzene concentration of $150 \mathrm{ppt}$. If the detection limit is taken as three times the standard deviation, this converts to $450 \mathrm{ppt}$, which is, to our 

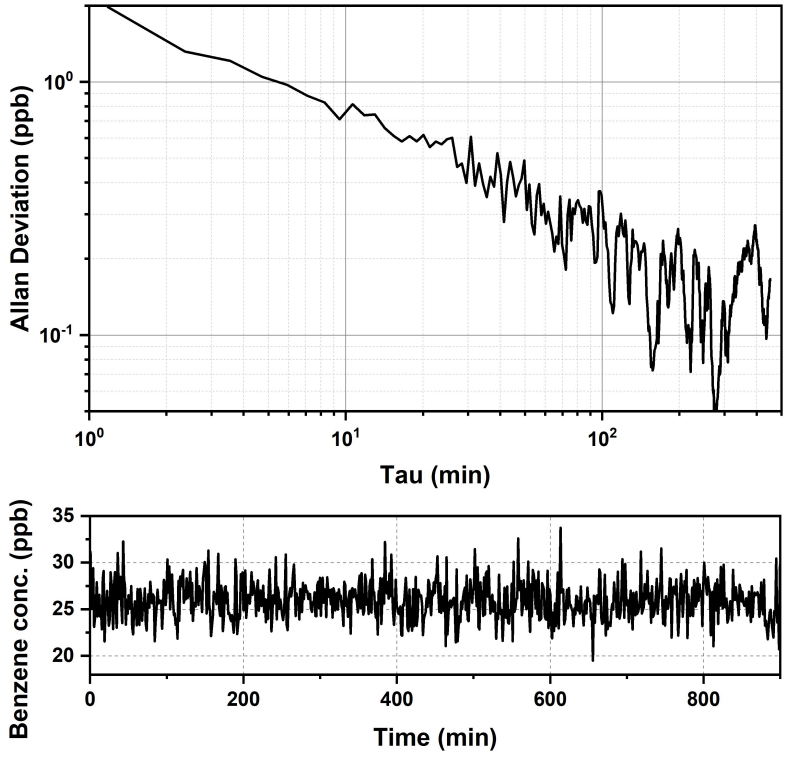

Fig. 7. Allan deviation of a benzene concentration measurement with a $26 \mathrm{ppb}$ sample of benzene (above) and the time trace used to calculate the deviation (below).

knowledge, lowest reported in the literature for optical benzene sensors. Furthermore, the benzene $v_{4}$ band used here in the spectroscopic measurements is free of spectral overlap from many common interferents, such as toluene and xylenes, which solves a typical shortcoming of benzene detectors based on infrared spectroscopy.

Funding. Jenny and Antti Wihuri Foundation; "Investment for the Future" program (Equipex EXTRA, ANR-11-EQPX-0016).

Disclosures. TH: Gasera Ltd. (E).

\section{REFERENCES}

1. J. Peltola, T. Hieta, and M. Vainio, Opt. Lett. 40, 2933 (2015).

2. T. Tomberg, M. Vainio, T. Hieta, and L. Halonen, Sci. Reports 8, 1848 (2018).

3. C. Hirschmann, S. Sinisalo, J. Uotila, S. Ojala, and R. Keiski, Vib. Spectrosc. 68, 170 (2013).

4. C. B. Hirschmann, N. S. Koivikko, J. Raittila, J. Tenhunen, S. Ojala, K. Rahkamaa-Tolonen, R. Marbach, S. Hirschmann, and R. L. Keiski, Sensors. 11, 5270 (2011).

5. M. T. Smith, Annu. Rev. Public Heal. 31, 133 (2010).

6. L. Wallace, Environ. Heal. Perspectives 104, 1129 (1996).

7. M.-Y. Zhu, L.-X. Zhang, J. Yin, J.-J. Chen, and L.-J. Bie, Inorg. Chem. Front. 5, 3046 (2018).

8. R. Sur, Y. Ding, R. Jackson, and R. Hanson, Appl. Phys. B 125, 195 (2019).

9. J. Cousin, W. Chen, D. Bigourd, M. Fourmentin, and S. Kassi, Appl. Phys. B 97, 919 (2009).

10. W. Chen, F. Cazier, F. Tittel, and D. Boucher, Appl. Opt. 39, 6238 (2000).

11. J. Berger and V. V. Pustogov, Infrared Phys. \& Technol. 37, 163 (1996).

12. C. R. Young, N. Menegazzo, A. E. Riley, C. H. Brons, F. P. DiSanzo, J. L. Givens, J. L. Martin, M. M. Disko, and B. Mizaikoff, Anal. Chem. 83, 6141 (2011).

13. C. Mikhailenko, Y. L. Babikov, and V. Golovko, Atmospheric Ocean. Opt. 18, 685 (2005).

14. A. N. Baranov, M. Bahriz, and R. Teissier, Opt. Express 24, 18799 (2016).
15. H. Nguyen Van, Z. Loghmari, H. Philip, M. Bahriz, A. Baranov, and R. Teissier, Photonics 6, 31 (2019). 


\section{FULL REFERENCES}

1. J. Peltola, T. Hieta, and M. Vainio, "Parts-per-trillion-level detection of nitrogen dioxide by cantilever-enhanced photo-acoustic spectroscopy," Opt. Lett. 40, 2933-2936 (2015).

2. T. Tomberg, M. Vainio, T. Hieta, and L. Halonen, "Sub-parts-per-trillion level sensitivity in trace gas detection by cantilever-enhanced photoacoustic spectroscopy," Sci. Reports 8, 1848 (2018).

3. C. Hirschmann, S. Sinisalo, J. Uotila, S. Ojala, and R. Keiski, "Trace gas detection of benzene, toluene, $\mathrm{p}$-, $\mathrm{m}$ - and o-xylene with a compact measurement system using cantilever enhanced photoacoustic spectroscopy and optical parametric oscillator," Vib. Spectrosc. 68, $170-$ 176 (2013).

4. C. B. Hirschmann, N. S. Koivikko, J. Raittila, J. Tenhunen, S. Ojala, K. Rahkamaa-Tolonen, R. Marbach, S. Hirschmann, and R. L. Keiski, "Ft-ir-cpas-new photoacoustic measurement technique for analysis of hot gases: a case study on vocs," Sensors. 11, 5270-5289 (2011).

5. M. T. Smith, "Advances in understanding benzene health effects and susceptibility," Annu. Rev. Public Heal. 31, 133-148 (2010).

6. L. Wallace, "Environmental exposure to benzene: an update." Environ. Heal. Perspectives 104, 1129-1136 (1996).

7. M.-Y. Zhu, L.-X. Zhang, J. Yin, J.-J. Chen, and L.-J. Bie, "Ppt-level benzene detection and gas sensing mechanism using (c4h9nh3)2pbi2br2 organic-inorganic layered perovskite," Inorg. Chem. Front. 5, 30463052 (2018).

8. R. Sur, Y. Ding, R. Jackson, and R. Hanson, "Tunable laser-based detection of benzene using spectrally narrow absorption features," Appl. Phys. B 125, 195 (2019).

9. J. Cousin, W. Chen, D. Bigourd, M. Fourmentin, and S. Kassi, "Telecomgrade fiber laser-based difference-frequency generation and ppb-level detection of benzene vapor in air around $3 \mu \mathrm{m}$," Appl. Phys. B 97, 919 (2009).

10. W. Chen, F. Cazier, F. Tittel, and D. Boucher, "Measurements of benzene concentration by difference-frequency laser absorption spectroscopy," Appl. Opt. 39, 6238-6242 (2000).

11. J. Berger and V. V. Pustogov, "Monitoring of benzene in the $10 \mu \mathrm{m}$ and $14 \mu \mathrm{m}$ region," Infrared Phys. \& Technol. 37, 163 - 166 (1996).

12. C. R. Young, N. Menegazzo, A. E. Riley, C. H. Brons, F. P. DiSanzo, J. L. Givens, J. L. Martin, M. M. Disko, and B. Mizaikoff, "Infrared hollow waveguide sensors for simultaneous gas phase detection of benzene, toluene, and xylenes in field environments," Anal. Chem. 83, 6141-6147 (2011).

13. C. Mikhailenko, Y. L. Babikov, and V. Golovko, "Information-calculating system spectroscopy of atmospheric gases. the structure and main functions," Atmospheric Ocean. Opt. 18, 685-695 (2005).

14. A. N. Baranov, M. Bahriz, and R. Teissier, "Room temperature continuous wave operation of inas-based quantum cascade lasers at $15 \mu \mathrm{m}$," Opt. Express 24, 18799-18806 (2016).

15. H. Nguyen Van, Z. Loghmari, H. Philip, M. Bahriz, A. Baranov, and R. Teissier, "Long wavelength $(\lambda>17 \mu \mathrm{m})$ distributed feedback quantum cascade lasers operating in a continuous wave at room temperature," Photonics 6, 31 (2019). 